\title{
Visualization and diagnostics of reliability of the object with changing the functioning conditions
}

\author{
Evgeny Gvozdev ${ }^{*}$ \\ Moscow State University of Civil Engineering, Yaroslavskoe shosse, 26, Moscow, 129337, Russia
}

\begin{abstract}
The object of the scientific research is buildings (structures), which requiring the determination of a reliability indicator for their further operation in new operating conditions, the determination of additional loads in the form of (explosions, fires, vibration processes). The solution to such problems is relevant for buildings (structures), which are acquired (leased) by the owner, for their further operation in the new conditions of the technological process associated with the handling, storage, processing and production of fire and explosion hazardous substances (materials). It is important to determine the readiness of buildings (structures) for operation in the new conditions of functioning of the technological process of production, it is proposed to use deterministic, statistical and probabilistic approaches. It is proposed to use a simplified assessment of the safety margin of a building (structure) by yield strengths (for steel elements) and strength (for base materials, load-bearing walls, partitions and ceilings) corresponding to the maximum allowable values for their destruction. The innovative approach is described that allows us to solve the problems of assessing the strength reliability of structural elements of buildings (structures) to obtain guaranteed characteristics of a given margin of safety, its resistance to possible realized effects (explosions, fires, vibration processes)
\end{abstract}

\section{Introduction}

The issues of fire and explosion safety of objects of protection of the technosphere space are currently priority. Objects of protection of the technosphere is the whole tangible surrounding world around us created by humanity, and people themselves are also objects of protection from various kinds of technological hazards [1]. Safety from explosions and fires in the technosphere is one of the main tasks of the two subsystems (fire and industrial safety) included in the integrated safety system of a manufacturing enterprise because the main share of all hazards (about 70\%) falls on the system in question (Fig. 1). The required level of safety of objects to be protected from various hazardous influences is achieved by maintaining the required safety coefficient in the considered subsystems (figure 1), in the form of a ratio:

$$
\varphi_{c s} \geq \varphi_{c d i}
$$

\footnotetext{
* Corresponding author: evgvozdev@mail.ru
} 
where $\varphi_{c s}$ is the calculated and maintained coefficient of the security level;

$\varphi_{c d i}$ is the value of the maximum coefficient of the level of destructive impact on the subsystem $[2,3]$.

In Russia, the situation related to fires and explosions at production facilities should be assessed as rather complicated, requiring constant attention not only from the authorities of the State Power, but also from owners (legal entities) of production enterprises, which, in accordance with the requirements of the Federal Law of the Russian Federation of 21.12.1994 No.69-FZ "About fire safety", they are personally responsible for maintaining the required level of fire protection at their property rights.

Every year in Russia, housing stock is destroyed with a total area equivalent to a city with a population of 10-20 thousand people from fires and explosions, where the main reason for their implementation is poor-quality compliance with the fire and explosion protection requirements of buildings (structures) specified in the requirements of documents (Federal Law of the Russian Federation of 30.12.2009 No.123-FZ " Technical regulation on fire safety requirements" (in Russian); Decree of the Government of the Russian Federation No. 390 "On the fire-fighting regime" of 04.25.2012 (in Russian)).

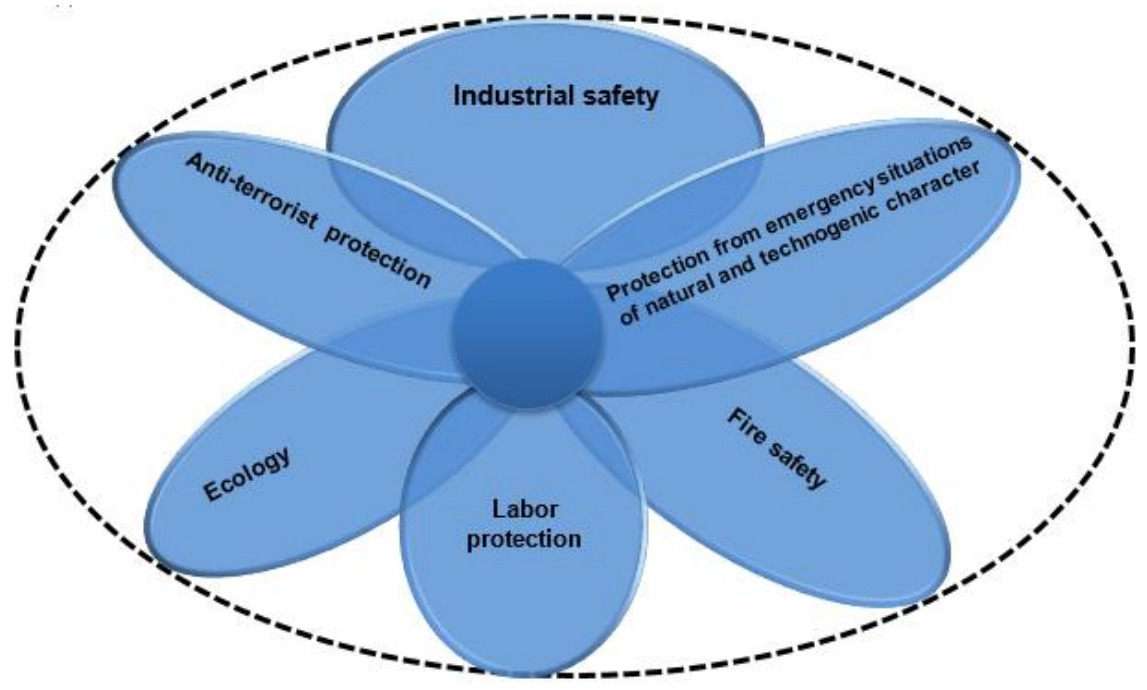

Fig. 1. Integrated enterprise security system.

With the transition of Russia to a new level of economic development (the period covered from the end of 1990 to the present), there have been events in the mass sale and lease of buildings, structures, their complexes, which are unprofitable and require significant investments.

Based on the analysis of statistics in the Russian Federation, reflecting the indicators of mass sales and leasing of buildings, structures, their complexes (for the period from the end of 1990 to the present), it is noted:

- $\quad$ at real estate, (about 70\%), the class of functional fire hazard (FFH) was changed;

- real estate objects were demolished, in their place new objects were built or planned to be built (about 10-15\%);

- only the remaining share of immovable objects began to be used in accordance with the established class of FFH prescribed in the project (about 10-15\%) (Information letter from the Head of FSBI VNIIPO EMERCOM of Russia No 1993-1-29-11-6 of 11.18.2019 "On the provision of fire accounting cards" (in Russian)). 
However, not all owners of buildings (premises) purchased or leased, fully complied with the requirements established by regulatory legal acts and regulatory documents on fire safety (Federal Law of the Russian Federation of 30.12.2009 No.384-FZ "Technical Regulations on the Safety of Buildings and Structures"; SP 12.131.30. 2009 "Definition of categories of premises, buildings and outdoor installations for explosion and fire hazard"; Standard GOST R 12.3.047-2012 "Fire safety of technological processes, General requirements. Control methods" (in Russian)), for many unscrupulous legal entities the main goal is to make profit at the lowest cost and costs.

According to the results of statistics, the occurrence of fires and explosions over a period of 10 years (from 2007 to 2017), in buildings (rooms) operated under the conditions of a technological process associated with the effects of additional loads in the form of possible explosions, fires, vibration processes, structures collapsed (about 50\%) precisely at the objects acquired (leased), which needed to change the class of FFH (Information letter from the Head of FSBI VNIIPO EMERCOM of Russia No 1993-1-29-11-6 of 11.18.2019 "On the provision of fire accounting cards" (in Russian)).

The information presented required the development of a new scientific approach to assessing the readiness of buildings (structures) for changing the class of functional fire hazard, during their further operation in a process associated with the effects of additional loads in the form of possible explosions, fires, vibration processes.

\section{Methodology}

In fundamental research and development that has an applied aspect to increasing the stability of the functioning of physical objects, from the point of view of strength, reliability, survivability, and resource, determinate, statistical, and probabilistic approaches and their criteria characteristics are used, as a rule, to determine indicators of safe permissible states [4].

One of the main modern means of ensuring safety has been the use of information technologies based on the methods and means of engineering and construction diagnostics (ECD) is a field of knowledge that encompasses the theory, methods and means of determining the technical condition of an engineering is constructive object (ECO) [5]. All methods that allow you to obtain information about the technical condition of ECO, in order to assess the continuation of its use, relate to engineering and construction diagnostics. It is used in various industries, inevitably fragmenting into separate areas, depending on the types of diagnostic objects: computer technology; devices for various purposes; aerospace and military installations; agricultural machines; agricultural equipment; building construction; ECO used at a hazardous industrial facility (HIF), etc. For all these objects, it is inevitable to use ECD methods that have specific features for each type.

In ongoing research in the field of integrated safety of buildings (structures), the fulcrum is the application of the methods of the following groups:

1. Group of methods aimed at identifying risks.

2. Groups of methods aimed at assessing the physical stability of buildings (structures).

3. Groups of methods aimed at assessing the realized dangers that arose as a result of violation of the operating conditions of the technological process $[6,7]$.

Methods of group 1 are presented in the table 1. 
Table 1. The main methods for risk identification

\begin{tabular}{|c|c|}
\hline Methods & \multicolumn{1}{|c|}{ Main purpose } \\
\hline Preliminary Hazard Analysis & $\begin{array}{r}\text { The identification of dangerous situations and events that } \\
\text { occurred during the period under review caused damage to the } \\
\text { building (structure), equipment or system. }\end{array}$ \\
\hline $\begin{array}{c}\text { Hazard Analysis and Critical } \\
\text { Points }\end{array}$ & $\begin{array}{r}\text { Minimizing risk by applying controls in the production process of } \\
\text { products manufactured in a building (structure). }\end{array}$ \\
\hline Scenario analysis & $\begin{array}{c}\text { Consideration of the probability of possible dangerous events in } \\
\text { the future and study of their significance in terms of impacts on } \\
\text { the sustainability of buildings (structures). }\end{array}$ \\
\hline $\begin{array}{c}\text { The arrangement of possible cause and effect factors into } \\
\text { generalized categories so that all possible hypotheses of the } \\
\text { occurrence and development of dangerous events can be } \\
\text { investigated. }\end{array}$ \\
\hline
\end{tabular}

The methods presented for consideration are directly related to expert assessment through risk assessment, aimed at obtaining the results of assessing the qualitative characteristics of the functioning of a building (structure) (The disposal of PJSC "Gazprom" №394 from 28.11.2017 G. "Guidelines for risk management using qualitative assessments" (in Russian)).

The advantage of the considered the first group of methods is:

- $\quad$ the ability to describe and assess risks in a short time, in their ranking;

- $\quad$ the ability to determine the causes and factors affecting the level of risk, as well as to determine the highest priority risks to management, to develop strategies (methods) for their response [8;9].

The practical implementation of the considered group of methods is based on expert assessment of the qualitative characteristics of the process of functioning of the facility, i.e. on a subjective assessment of the expected parameters of production activity in the building (structure).

The advantage in applying the methods of the first group is the prompt receipt of information for timely management decisions and relatively low costs. The disadvantage is the relatively high level of subjectivity and, as a consequence, the lack of confidence in the reliability of the estimates obtained due to errors.

Using methods of the second group, an indicator for assessing the state of a building (structure) is determined, which is presented in a quantitative measure, the list of such methods includes:

- $\quad$ non-destructive testing method [10];

- $\quad$ method for calculating strength (current, predictive, under static, monotonous and cyclic loading, etc.) [11];

- $\quad$ method for assessing the condition of the material used for the construction and decoration of the building (structure) [12];

- method for calculating the initial and residual resource in relation to the operating conditions of the building (structure) [13].

Since until recently, all these groups of methods presented for consideration were used independently of each other, it became necessary to formulate the integrated use of the methods in question with the aim of significantly increasing the level of integrated safety of buildings (structures) [14]. 
Methods of the third group, cover the following industry areas included in Integrated Security Systems of enterprises are industrial safety and fire safety. The group of methods under consideration is directly related to the production functioning process, in which explosive and fire hazardous substances are handled, stored, processed, and produced. That is, the purpose of applying this group of methods is to consider the process of exposure to hazards in the form of explosions or fires on ECO, which can occur from a medium with explosive and fire hazardous gas mixtures resulting from a violation of the technological process $[15 ; 16]$.

To determine the indicators associated with the effects of explosions (development of an industrial area of industrial safety), special mathematical methods are applied, based on the exact solution of systems of differential equations in partial derivatives, the so-called (CFD methods). The most effective CFD modeling tool currently used for modeling emergency processes is the FLACS software package (developed by the Norwegian company GEXCON) [17].

An example of information output with three-dimensional visualization of the risk of explosion, issued by the FLACS-Risk software package (Fig. 2)

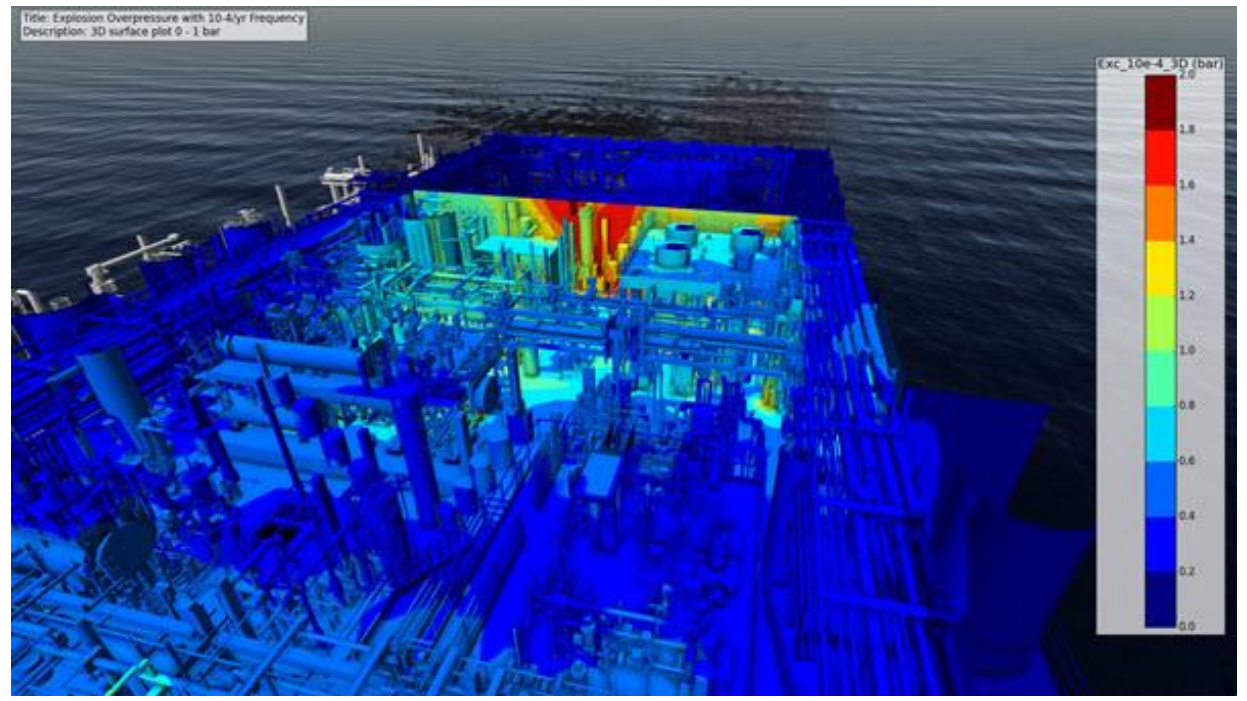

Fig. 2. Visualization of the place of the explosion (fire) implementation.

To determine the indicators associated with the effects of fires (development of the industry direction of fire safety), various software products are used, among which the PyroSim software, which provides fast and accurate operation in the form of a fire dynamics simulator (FDS), is considered the most popular. The PyroSim software under consideration is a graphical user interface for FDS that allows you to quickly, conveniently create, edit and analyze complex models of fire development $[18,19]$.

However, the software products submitted for consideration require high-quality input of input data, they must be developed and improved, namely:

- It is required to develop methods for calculating the parameters of physicochemical processes occurring in the flame zone and inside combustible material;

- It is required to develop mathematical models of turbulent heat and mass transfer and radiant heat transfer, as well as the mutual influence of radiation and turbulence. 
It is possible to solve such problems in a complex, with the help of engineering and construction diagnostics of buildings (structures), the current stage of development of technical control, which has reached a higher level.

\section{Results}

The implementation of approaches related to the assessment of the risk of technological hazards is currently an urgent tool for identifying hazards, predicting the reliability and sustainability of buildings and structures when implementing the effects of beyond design loads.

Based on the requirements of the Federal Law of the Russian Federation of 21.07.1997 No.116-FZ "On industrial safety of hazardous production facilities", buildings and structures at industrial facilities intended for the implementation of technological processes must undergo an industrial safety review. Examination of industrial safety of buildings and structures allows to evaluate:

- $\quad$ the degree of physical deterioration and the bearing capacity of building structures;

- $\quad$ defects, damage, changes in the characteristics of structures and materials;

- $\quad$ the possibility of further trouble-free operation.

When conducting an industrial safety examination, specialists often have to assess the condition of buildings and structures of the objects of examination at the place of their operation, i.e. carry out visual inspection and conduct visual measurement control.

For a quick assessment of the reliability of steel, reinforced concrete, stone and wooden structures based on the damage and defects present in them, as well as assessing the condition of a building and structure by the state of individual structures, "Recommendations for assessing the reliability of building structures by external signs" are used.

The evaluation of the indicator of the magnitude of the risk is used not only as a universal indicator providing a comprehensive analysis of safety, but also a tool to reduce the likelihood and consequences of accidents. The refined expression for risk assessment $\mathrm{R}$, can be represented as the following expression:

$$
R(a, t)=P_{f}(a, t) \cap \beta \cap L,
$$

where $P_{f}(a, t)$ is probability of a dangerous event; $a$ is a defect size; $t$ is a time; $\beta$ is a functional of the process of escalation of an emergency event (table 2); $L$ is an assessment of the result of destruction resulting from hazardous exposure. Symbol $\cap$ shows the logical operation of multiplication (product) of classes of events.

Table 2. The scale for assessing the reliability and probability of destruction of buildings (structures) by expert opinion

\begin{tabular}{|c|c|c|}
\hline $\begin{array}{c}\text { Conditional } \\
\text { reliability, } \boldsymbol{\beta}\end{array}$ & $\begin{array}{c}\text { Probability (frequency) of accidents per } \\
\text { year }\end{array}$ & $\begin{array}{c}\text { Expert reliability rating } \\
\text { scale }\end{array}$ \\
\hline 1 & $10^{-6}$ & good \\
\hline 0,8 & $10^{-5}$ & satisfactory \\
\hline 0,6 & $10^{-4}$ & unsatisfactory \\
\hline 0,4 & $10^{-3}$ & unacceptable \\
\hline
\end{tabular}

Currently, it is considered possible to assess the likelihood of destruction of a building (structure) based on the application of recommendations [20], which are based on the use of an express survey of the technical condition of buildings (structures). The overall 
assessment obtained by using an express examination is formed according to the results of the identified characteristic lesions.

The value of damage to building structures after $t$ years of operation, is determined by the formula

$$
\varepsilon=1-e^{-\lambda \cdot t}
$$

where $\lambda$ is a depreciation coefficient determined by survey data. Depreciation coefficient $\lambda$ can be calculated by the formula:

$$
\lambda=\frac{-\ln y}{t_{\phi}}
$$

where $y$ is a relative reliability, determined by the category of technical condition of the structure; $t_{\phi}$ is life in years at the time of the survey.

The term of operation of the structure before capital repair in years is determined by the formula:

$$
t_{K}=\frac{0,16}{\lambda}
$$

where $\lambda$ is a deterioration factor.

The term of operation of the structure to the emergency state in years is determined by the formula:

$$
t_{A}=\frac{0,22}{\lambda}
$$

A relative assessment of the reliability of a building or structure is made according to the formula:

$$
y=1-\varepsilon
$$

A general assessment of the damage to a building (structure) is made according to the formula:

$$
\varepsilon=\frac{\alpha_{1} \cdot \varepsilon_{1}+\alpha_{2} \cdot \varepsilon_{2}+\cdots+\alpha_{i} \cdot \varepsilon_{i}}{\alpha_{1}+\alpha_{2}+\cdots+\alpha_{i}}
$$

Where $\varepsilon_{1}, \varepsilon_{2} \ldots \varepsilon_{i}$ are maximum damage to certain types of structures;

$a_{1}, a_{2} \ldots a_{i}$ the coefficient of significance of certain types of structures.

Assessment of the technical condition of steel, reinforced concrete, stone and wooden structures based on the damage they contain is given in the tabular data of the document [20].

However, when implementing the considered methods of visual inspection and conducting visual measurement control, built on the basis of expert evaluation, it requires verification of the obtained indicators from the point of view of reliability.

To solve practical problems, a simplified assessment of the safety margin of a building (structure) $-n$ by yield strengths is used $-\sigma_{T}$ (for steel elements) and strength - $\sigma_{B}$ (for base materials, load-bearing walls, partitions, and ceilings) corresponding to the specified fracture probabilities - $P$ :

$$
\left(n_{T}\right)_{P}=\frac{\left(n_{T}\right)_{P}}{\left(\sigma^{\ni}\right)_{P}} ;\left(n_{B}\right)_{P}=\frac{\left(n_{B}\right)_{P}}{\left(\sigma^{\ni}\right)_{P}}
$$

Figures 2, 3 show the functions $\mathrm{P}$ of the distribution of the operational characteristics of the building (structure) $P\left(\sigma^{\ni}\right)$, yield properties of materials $P\left(\sigma_{T}\right)$ (for steel elements) and strength $P\left(\sigma_{B}\right)$ (for base materials, load-bearing walls, partitions and ceilings) (Fig. 1) and the distribution density function $f(\sigma)$ to assess the likelihood of destruction at the 
limit (receiving damage) of dangerous effects (explosion, fire, vibration, etc.) on the building (structure) with a probability $P(K)$ (Fig. 3) [21].

Operational characteristics of the building (structure) $P\left(\sigma^{\ni}\right)$ and yield properties of materials $P\left(\sigma_{T}\right)$ (for steel elements) and strength $P\left(\sigma_{B}\right)$ (for base materials, loadbearing walls, partitions and ceilings) correspond to probability $P(K)$ (Fig. 3) or failure probability density $f(K)$ at the point $K$ (Fig. 3 ):

$$
P_{(K)}=\left\{P_{(K T)}, P_{(K B)}\right\}
$$

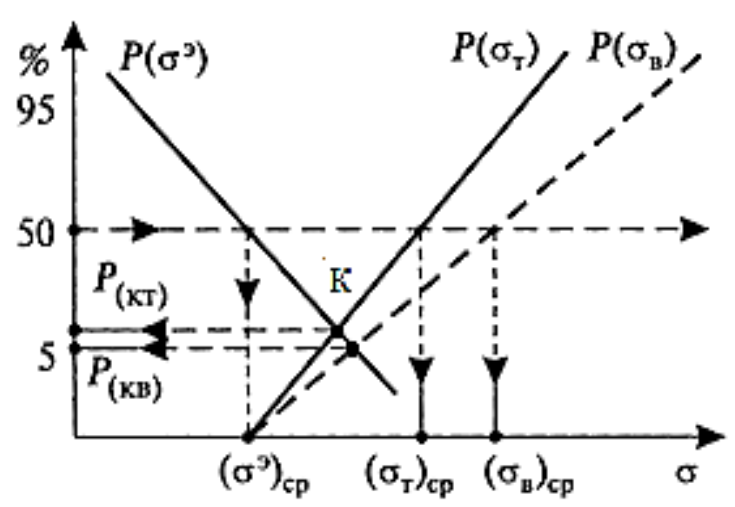

Fig 3. The scheme of the probabilistic assessment of strength in the calculation of the realized hazard.

The presented (Fig. 3) reduced value of the hazardous exposure $\bar{\sigma}_{C}$, characterized by the properties of materials according to yield strengths $P\left(\sigma_{T}\right)$ (for steel elements) and strength $P\left(\sigma_{B}\right)$ (for base materials, load-bearing walls, partitions and ceilings) (Fig. 4). Stress limit $\left(\sigma_{C}\right)$ characterizing the "strength" of materials $\left(\sigma_{T}\right)$ and $\left(\sigma_{B}\right)$ also a random variable. If the distribution density functions become known materials $f\left(\sigma^{\ni}\right)$ for existing $\sigma^{\ni}$ and $f\left(\sigma_{C}\right)$ for the indicator of ultimate impacts on the "strength" of materials $\left(\sigma_{T}\right)$ and $\left(\sigma_{B}\right)$ (Fig. 3), then by considering the given ratio of the segments $\left(\sigma_{C}\right)$ and $\left(\sigma_{\max }^{\ni}\right)$ by expression (3), the "strength" of buildings (structures) will be calculated. At the point $k$ the curves intersect, which indicates the probability of a possible destruction of buildings (structures), provided that two inequalities are satisfied:

$$
\sigma^{\ni} \geq \sigma_{K} ; \sigma_{C} \leq \sigma_{K}
$$




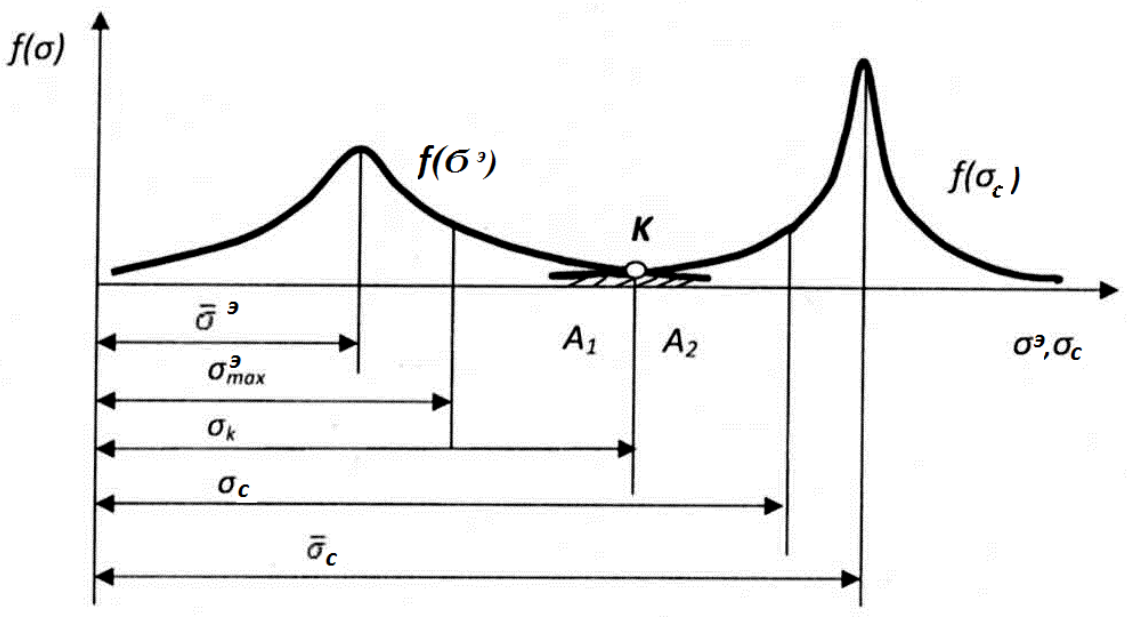

Fig. 4. Density distribution curves and safety margin.

In this case, the probability of destruction, considering the events in expression (6) with the indicated inequalities independent, will be represented by the formula:

$$
P_{\text {destr }}=P\left(\sigma^{\ni} \geq \sigma_{K}\right) P\left(\sigma_{C} \leq \sigma_{K}\right)=A_{1} \cdot A_{2},
$$

where $\sigma_{K}$ is stress at the intersection of the distribution density curves $\left(\mathrm{A}_{1}\right.$ и $\left.\mathrm{A}_{2}\right)$, areas of shaded areas shown in Fig. 5. Assuming that the operational and ultimate stresses are distributed according to the normal law, taking into account inequality (7), the probability of failure will be equal to:

$$
P_{\text {destr }}=\left[\frac{1}{2}-f\left(\frac{\sigma_{K}-\bar{\sigma}^{\ni}}{S_{\ni}}\right)\right] \times\left[\frac{1}{2}+f\left(\frac{\sigma_{K}-\bar{\sigma}_{C}}{S_{C}}\right)\right],
$$

where $\bar{\sigma}^{\ni}$ and $\bar{\sigma}_{C}$ are the average values of the designed (operational) and probabilistic (ultimate for hazardous effects) on the building (structure) and ultimate stresses $\sigma_{K}$ on materials according to yield strengths (for steel elements) and strength (for base materials, load-bearing walls, partitions and ceilings).

$S_{\ni}$ and $S_{C}$ are average quadratic deviations in distributions.

Then reliability (probability of non-destruction) $P_{(N)}$ carrier element will be equal:

$$
P_{(N)}=1-P_{\text {dest } r}
$$

Value calculation $\sigma_{K}$ can be implemented on the basis of distribution functions analytically in the presence of known, or in the absence of known on the basis of experiments.

When considering cases where voltage $\sigma^{\ni}$ and $\sigma_{T}=\sigma_{C}$ will be considered as random variables $\sigma_{B}=\beta$ and $\sigma^{\ni}=\alpha$ with parameters known for the normal distribution law, we obtain a function for a random variable $\psi$ (Fig. 5), which will be equal:

$$
F_{(\psi)}=\frac{1}{2}+F\left(\frac{\psi-\bar{\psi}}{S_{\psi}}\right)
$$

where $\psi=\sigma_{B}-\sigma^{\ni}=\beta-\alpha$, then $F(x)=\frac{1}{\sqrt{2 \pi}} \int_{0}^{x} \exp \left(-\frac{t^{2}}{2}\right) d t$ (Laplace function) 


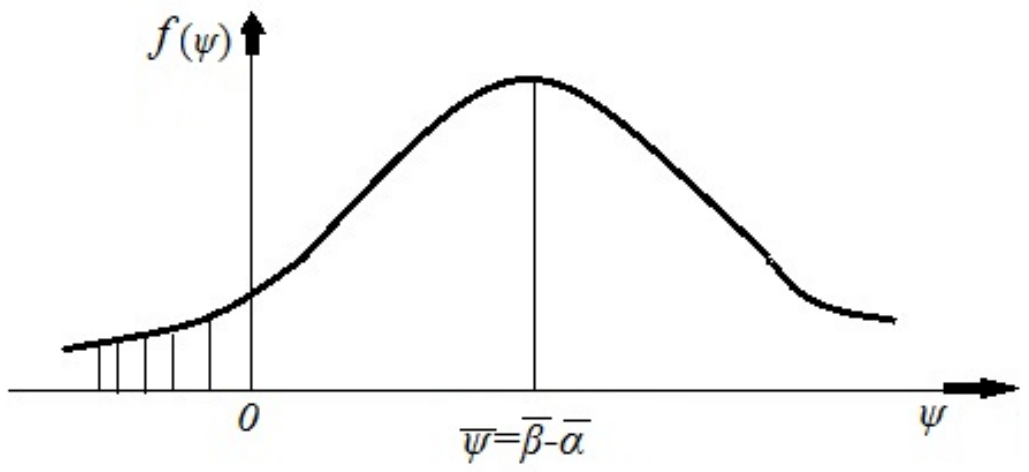

Fig. 5. The density curve of the distribution of the non-destruction function.

If at the same time random values of strength characteristics $\sigma_{B}$ or $\sigma_{T}$ and load characteristics $\sigma^{\ni}$ considered almost independent random variables (i.e. there is no correlation between them), then the parameters of the nondestructive function will be determined as $\psi=\sigma_{B}-\sigma^{\ni}=\bar{\beta}-\bar{\alpha}$ (mean value):

$$
S_{\psi}=\sqrt{S_{\beta}^{2}}+S_{\alpha}^{2}
$$

where $\psi$ is mean value, $S_{\psi}$ is standard deviation. Then the coefficient of variation:

$$
v_{\psi}=\frac{S_{\psi}}{\bar{\psi}}=\frac{\sqrt{S_{\beta}^{2}}+S_{\alpha}^{2}}{\bar{\beta}-\bar{\alpha}} .
$$

With this consideration of the problem, the probability of destruction will meet the condition $\psi=\sigma_{B}-\sigma^{\ni}<0$ (shaded area, fig. 5), and the formula for determining the probability of destruction will take the form:

$$
P_{\text {destr }}=P(\psi \leq 0)=F(0)
$$

Given equalities (10) and (12), the probability of destruction will be expressed by the formula:

$$
P_{\text {destr }}=\frac{1}{2}-F\left(\frac{\bar{\psi}}{S_{\psi}}\right)=\frac{1}{2}-F\left(\frac{1}{v_{\psi}}\right)
$$

The presented formulas in expressions (2-13) allow us to establish a relationship between the margin $n$ and the probability of destruction $P_{d e s t r}$, while dividing the numerator and denominator of the ratio for the coefficient of variation $v_{\psi}$ on $\bar{\alpha}$, the expression will be received:

$$
v_{\psi}=\frac{\sqrt{v_{\alpha}^{2}}+\bar{n}^{2} v_{\beta}^{2}}{n-1},
$$


where $v_{\alpha}=\frac{S_{\alpha}}{\bar{\alpha}}$ and $v_{\beta}=\frac{S_{\beta}}{\bar{\beta}}$ accordingly, the variation coefficients of the operating and breaking stresses; $\bar{n}$ is voltage margin according to their average values $n=\frac{\bar{\beta}}{\bar{\alpha}}$. The final formula will be presented as follows:

$$
P_{d e s t r}=\frac{1}{2}-F\left(\frac{\bar{n}-1}{\sqrt{v_{\alpha}^{2}+\bar{n}^{2} v_{\beta}^{2}}}\right)
$$

It follows from the relation presented in formula (19) that the probability of fracture decreases with increasing safety factor $\bar{n}$ according to the average values of destructive and effective stresses.

As a result, having accepted, as a first approximation, the assumption of a normal law of distribution of the operational load and bearing capacity of a structural element and knowing the actual (or given) values of the variation coefficients, there is an opportunity to determine the relationship between the probability of destruction $P_{\text {destr }}$ and reserves $n$ for various buildings (structures) when assessing decisions in technological safety based on a risk assessment [21, 22].

Further, the presented approach based on the dependence $P_{\text {destr }}$ on strength $\bar{n}$ according to the average values of destructive and effective stresses, it requires studies on the likely danger of the environment of the functioning of the production process, when there is a need to change the class of functional fire hazard.

With the functioning of the production process associated with the handling, storage and processing of fire and explosion hazardous substances and materials inside the ECO, conditions can be created for the occurrence of emergency explosions inside buildings (structures), characterized mainly by the deflagration type of explosive transformation. The development has proposed many ways to reduce explosive impact (EI) on the supporting structures of buildings (structures) [23], ranging from the use of various types of shutoffs, safety shields and valves, ending with the use of safety and easy-to-reset structures as a reduction in the pressure of explosives. In the event of fires in buildings (structures), due to prolonged fire exposure to high temperatures on structural materials, changes occur inside them associated with the deformation, destruction or complete destruction (burning out) of a part of the building (structure). Given the fact that mainly supporting structures are made of reinforcement and concrete, concrete is able to collapse under prolonged exposure to high temperatures. The dependences between the temperature limit and the duration of the heat exposure, described in the works of researchers [24-27], who were involved in assessing the residual bearing capacity of structures after a fire, were established. However, there are other relevant features that remain poorly understood, are directly related to buildings that have been in operation for a long time (requiring a change in the class of functional fire hazard). The considered features include the use of the wear factor (brittleness), which depends on the duration (time criterion) and the medium (dry, wet, aggressive, etc.) (Fig. 6). It is the deterioration factor that will be the reduction factor $\lambda$ , upon receipt of calculations of the effect of fire on the bearing element of the reinforced concrete structure. 


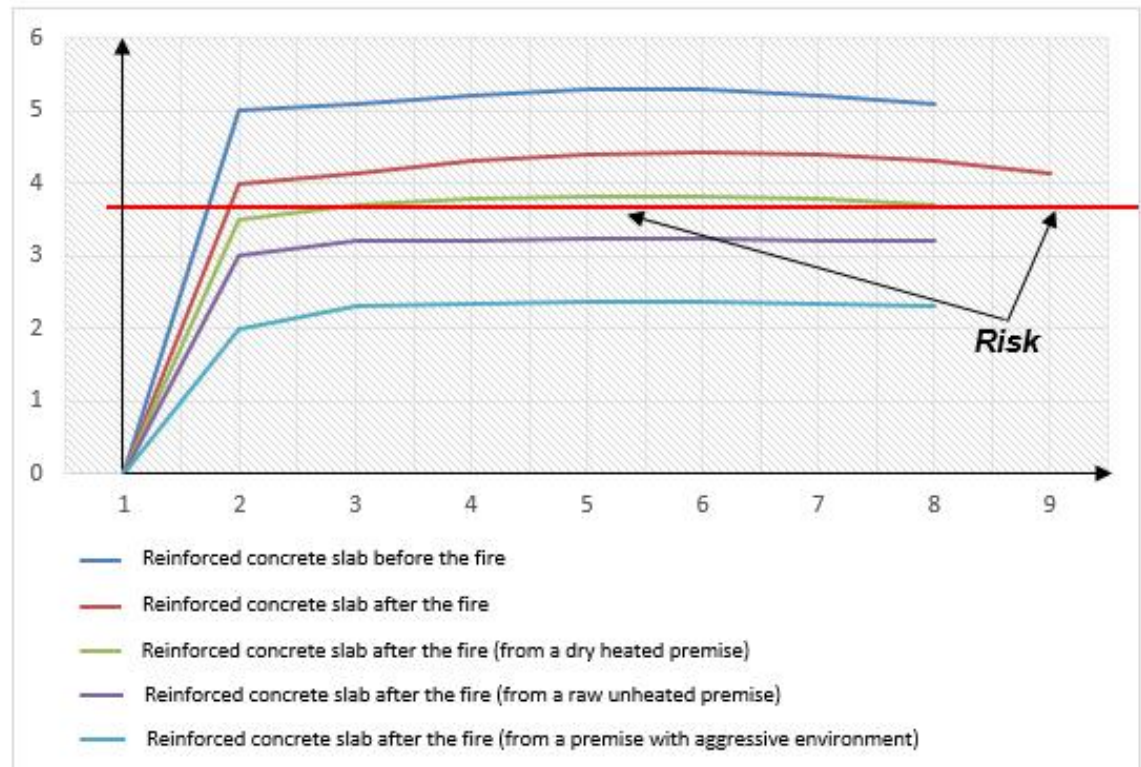

Fig. 6. Values of residual structural rigidity.

Thus, the significant difference presented (Fig. 6) between the change in the properties of materials before and after the fire is that the decrease in the bearing capacity during the thermal effect of the fire is due to the following characteristics that must be taken into account when assessing the reliability of a building (structure), namely:

- concrete deterioration (strength indicator);

- deterioration of the reinforcement (an indicator of elasticity).

The research results allow us to draw the following conclusions that the determination of the readiness indicator of a building (structure) for operation under the influence of dynamic loads in the form of (explosions, fires, vibration processes) is carried out in a complex, using the groups of methods that are presented in the content of the article.

\section{Conclusion}

The presented approach allows us to solve the problem of assessing the strength reliability of structural elements of buildings (structures), when it is important to be able to obtain guaranteed characteristics of a given margin of safety, its resistance to possible realized effects (explosions, fires, vibration processes). A certain breakthrough was recorded in the use of defective information to calculate the probability of destruction. It is required to develop methods for calculating the probability of destruction of ECO using information obtained when performing ECD. Using the material in order to determine reliability indicators on the basis of risks allows us to consider the calculated values of the safety margin of a building (structure), which meets the established requirements for evaluating effectiveness from the point of view of theory and practice of operations research. The described approach is innovative and representative, correctly reflects the essence and target function of security, allows you to take into account the features of the functioning of each of the presented indicators, taking into account the characteristics of the connectedness between them. 


\section{References}

1. E. V. Gvozdev, \& Y. G. Matvienko. Comprehensive Risk Assessment at the Life Support Enterprises with Hazardous Production Facilities. Occup. Saf. Ind. 2019, 6978 (2019). DOI: 10.24000 / 0409-2961-2019-10-69-78

2. Evgeny Gvozdev. On the probability determination of the reliability of a technosphere object under hazardous influence. IOP Conf. Ser. Mater. Sci. Eng. 86905204 (2020) doi:doi:10.1088/1757-899X/869/5/052043

3. E. V. Gvozdev. Methodology for the synthesis of an adaptive integrated security system at a regional life support enterprise. Pozharovzryvobezopasnost/Fire Explos. Saf. (2020) doi:10.18322/PVB.2020.29.02.6-16

4. N. A. Makhutov, (2017). Generalized regularities of deformation and fracture processes. Herald of the Russian Academy of Sciences, 87(3), 217-228. https://doi.org/10.1134/S1019331617030030

5. N. A. Mahutov, V. I. Ivanov, V. V. Musatov. Application of technical diagnostics for calculating the probability of destruction of technical devices and assessing the risk of an accident// Occupational safety in industry. - (2018). - № 9. - P. 53-64. DOI: 10.24000/0409-2961-2018-9-53-64

6. G. E. Vladimirovich, \& C. V. Mikhailovna, The Modern Strategy to the Process of Managing Complex Security of the Enterprise on the Basis of Rational Centralization. Int. J. Innov. Technol. Explor. Eng. 9, 4614-4620 (2019) doi 10.35940/ijitee.A4944.119119

7. N. A. Makhutov, et al. The impact of damaging factors of man-made emergencies on environmental safety. Safety and emergency issues 53-66 (2019) doi:10.36535/08694176-2019-06-7

8. A. Noroozi, , N. Khakzad, , F. Khan, , S. Mackinnon \& R. Abbassi, (2013). The role of human error in risk analysis: Application to pre- and post-maintenance procedures of process facilities. Reliability Engineering and System Safety, 119, 251-258. https://doi.org/10.1016/j.ress.2013.06.038

9. B. Kamsu-Foguem, (2016). Information structuring and risk-based inspection for the marine oil pipelines. Applied Ocean Research, 56, 132-142. https://doi.org/10.1016/j.apor.2016.01.009

10. O. A. Tsygankova, , D. M. Atabaeva, A. A. Shavaev, R. A. Girs \& A. A. Chetvertakov. Method of Non-Destructive Testing of Composite Materials. in Proceedings of the 2019 IEEE International Conference Quality Management, Transport and Information Security, Information Technologies IT and QM and IS 2019 (2019). doi:10.1109/ITQMIS.2019.8928409

11. E. C. Bentz, F. J. Vecchio \& M. P. Collins. Simplified modified compression field theory for calculating shear strength of reinforced concrete elements. ACI Struct. J. (2006) doi:10.14359/16438

12. N. Z. Muhammad et al. Tests and methods of evaluating the self-healing efficiency of concrete: A review. Construction and Building Materials (2016) doi:10.1016/j.conbuildmat.2016.03.017

13. J. Cai, G. Bu, C. Yang, Q. Chen \& Z. Zuo. Calculation methods for inter-story drifts of building structures. Adv. Struct. Eng. (2014) doi:10.1260/1369-4332.17.5.735

14. D. Minoli, K. Sohraby \& B. Occhiogrosso. Considerations, Requirements, and Architectures for Smart Buildings-Energy Optimization and Next-Generation 
Building Management Systems. IEEE Internet Things J. (2017) doi:10.1109/JIOT.2017.2647881

15. E. Yu. Kolesnikov, E. Telyakov. Quantitative assessment of emergency risk: estimation of parametric sensitivity of models and conservativeness of accepted assumptions// Occupational safety in industry. (2018) № 3. P. 63-67. DOI: 10.24000/0409-2961-2018-3-63-67

16. E. Yu. Kolesnikov. On the uncertainty of the value of the concentration limits of the flame propagation of combustible gas-steam-air mixtures// Occupational safety in industry. (2020) № 6. P. 89-94. DOI: 10.24000/0409-2961-2020-6-89-94

17. GESKON. FLACS software (2020). Website https://www.gexcon.com/productsservices/FLACS-Software/22/en. Date of appeal 07.16.2020

18. PyroSim. Field model of fire (2020), https://pyrosim.ru/polevaya-model-pozhara. Date of appeal 07.16.2020

19. FDS-SMV. Simulator of the dynamics of fire and smoke (2020), https://pages.nist.gov/fds-smv/. Date of appeal 07.16.2020

20. Recommendations for assessing the reliability of building structures of buildings and structures by external signs. "TsNIIpromzdaniy". (2001), Moscow, in Russian

21. A. S. Pecherkin (2017). Research Prospects in the Field of Risk Analysis for Improvement of Government Regulation and Safety Increase of the Oil and Gas Chemical Complex Objects. Occupational Safety in Industry, (9), 5-13. https://doi.org/10.24000/0409-2961-2017-9-5-13

22. V. V. Klyuev et al. 20TH NATIONAL CONFERENCE ON NON-DESTRUCTIVE TESTING AND TECHNICAL DIAGNOSTICS. Kontrol'. Diagnostika. (2014) doi:10.14489/td.2014.05.pp.005-016

23. E.Yu. Kolesnikov, E. Telyakov. Quantitative assessment of emergency risk: an assessment of the parametric sensitivity of models and the conservatism of the assumptions made. Labor safety in industry. (2018). 3. Pp. 63-67. DOI: $10.24000 /$ 0409-2961-2018-3-63-67

24. L. Gandossi, K. Simola \& B. Shepherd. The link between risk-informed in-service inspection and inspection qualification. Insight Non-Destructive Test. Cond. Monit. (2009) doi:10.1784/insi.2009.51.1.16

25. V.K. Kodur, A. Agrawal. An approach for evaluating residual capacity of reinforced concrete beams exposed to fire Eng. Struct. (2016) 110. Pp. 293-306 https://doi.org/10.1016/j.engstruct.2015.11.047

26. Y. Wang, et al. Analytical model for predicting the load-deflection curve of post-fire reinforced-concrete slab. Fire Saf. J. (2018) 101. Pp. 63-83. https://doi.org/10.1016/j.firesaf.2018.09.002

27. Fedorova N. V., Vu Ngok Tuen, Yakovenko I. A. Criterion of strength of a flatstressed reinforced concrete element under special impact. Vestnik MGSU. (2020). Vol. 15. Issue 11. pp. 1513-1522. DOI: 10.22227/1997-0935.2020.11.1513-1522 